\title{
A Comparative Study of the Efficacy of Cognitive Group Therapy and Aerobic Exercise in the Treatment of Depression among the Students
}

\author{
Khirollah Sadeghi ${ }^{1}$, Seyed Majid Ahmadi ${ }^{2}$, Seyed Mojtaba Ahmadi ${ }^{1}$, Mansour Rezaei ${ }^{3}$, Javad Miri ${ }^{4}$, Alireza \\ Abdi $^{5}$, Firoozeh Khamoushi ${ }^{6}$, Mahin Salehi ${ }^{7} \&$ Khadijeh Jamshidi ${ }^{6}$ \\ ${ }^{1}$ Department of Psychology, School of Medicine, Kermanshah University of Medical Sciences, Iran \\ ${ }^{2}$ Student of Internal Medicine, Student Research Committee, Kermanshah University of Medical Sciences, \\ Kermanshah, Iran \\ ${ }^{3}$ Department of Biological Statistics, Social Development and Health Promotion Research Center, Kermanshah \\ University of Medical Sciences, Iran \\ ${ }^{4}$ Nursing and Midwifery School, Kermanshah University of Medical Sciences, Kermanshah, Iran \\ ${ }^{5}$ Nursing and Midwifery School, Shahid Beheshti University of Medical Sciences (International branch), Tehran, \\ Iran \\ ${ }^{6}$ Student Research Committee, Kermanshah University of Medical Sciences, Kermanshah, Iran \\ ${ }^{7}$ Department of Physical Education, School of Physical Education, Science and Research Branch of Yasuj \\ Islamic Azad University, Iran \\ Correspondence: Seyed Mojtaba Ahmadi, Department of Psychology, Faculty of Medicine, Kermanshah \\ University of Medical Science, Iran. Tel: 98-091-7344-2881. E-mail: mojtabakmahmdi@yahoo.com
}

\author{
Received: November 25, 2015 Accepted: February 7, 2016 Online Published: February 24, 2016 \\ doi:10.5539/gjhs.v8n10p1 URL: http://dx.doi.org/10.5539/gjhs.v8n10p1
}

\begin{abstract}
Background: Depression is one of the most common mental disorders. Finding effective treatments for such a disorder with higher efficiency lower side effects and affordability is an active area of research in psychiatry. This study aimed to comparatively analyze the effects of the cognitive group therapy and aerobic exercises on depression, automatic negative thoughts and dysfunctional attitudes of students at Kermanshah University of Medical Science.

Methods: In this clinical trial, 46 associate and undergraduate students at Kermanshah University of Medical Science were randomly divided into three groups: cognitive therapy, aerobic exercise, and control. The data was gathered both before and 8 weeks after the intervention. Beck Depression Inventory (BDI-II), automatic negative thoughts (ATQ), and the Dysfunctional Attitude Scale (DAS) were used as the data collection instruments. The data were analyzed with SPSS version 15 using paired samples T-test, chi-square test, Kruskal-Wallis test, and analysis of variance (ANOVA).
\end{abstract}

Results: Cognitive therapy caused a significant decrease in depression, belief in automatic negative thoughts, and dysfunctional attitudes in comparison to the control group $(\mathrm{p}<0.05)$. Although aerobics compared to the control group causes more reductions in the variables, however, It was only meaningful for the depression variable ( $\mathrm{p}=0.049$ ). Cognitive therapy also reduced the variables more than the aerobic exercise, but the decrease was not statistically significant.

Conclusions: Cognitive group therapy and aerobic exercise are effective in treating depression. For treating depression, aerobic exercise can be used as a therapy itself or along with cognitive-behavioral therapy and pharmacotherapy.

Keywords: cognitive group therapy, aerobic exercise, depression, students

\section{Background}

Depression is one of the most common mental disorders and a general problem of human life which is often called the common cold of psychiatry disorder (Seligman, 1975; mentioned in Hawton et al., 1989). The main feature of this disorder is at least a two-week period in which a person is either depressed or loses his interest or 
pleasure in almost all his activities. Changes in appetite or weight, sleep and psychomotor activities, fatigue and loss of energy, which may appear in decreasing social, educational and occupational performances, feelings of worthlessness or guilt, thinking, concentrating or decision making problems, and thinking about or trying to commit a suicide, are from among other depression symptoms. In recent studies, major depression disorder has the highest lifetime prevalence among other psychiatric disorders (about 17\%) (Sadock et al., 2007). Studies of depression in student groups also show a high range of depression (Hashemi \& Kamkar, 2001; Ildarabady et al., 2004; Tavakoli zade \& Mohamadpoor, 2001; Zohoor \& Mosakhani, 2001). In recent years, many researchers confirm the usefulness and effectiveness of non- pharmacotherapy for depression. One of the nonpharmacotherapies of depression is cognitive therapy. Aaron T. Beck's cognitive therapy concentrates on cognitive changes that are supposed to have a role in the formation of depression. Cognitive therapy aims to relieve depression and prevent its recurrence through identifying negative cognitions, creating different, flexible and positive ways of thinking, and practicing cognitive and behavioral responses (Sadock et al., 2007). Studies on the efficacy of cognitive-behavioral group therapy for depression have shown that this treatment is effective in treating depression (Kahrizi et al., 2012; Taheri \& Jamshidifar, 2007). Studies have shown that although pharmacotherapy and cognitive-behavioral therapy are useful in the treatment of such a disorder, exercise can also be effective in the treatment for depression. Many studies have examined the effects of aerobic exercise on depression and revealed that aerobic exercise is effective in improving depression and it can lead to a reduction in the depression symptoms of patients (Dimeo et al., 2001; McCann \& Holmes, 1984; Zarshenas et al., 2008). Some studies have also represented that exercise has the same effect as cognitive therapy and pharmacotherapy. For example, in a study by Lawlor and Hopker in 2001, there were no significant difference between the effect of cognitive-behavioral therapy and exercise (Lawlor \& Hopker, 2001). In another study, exercise and treatment by antidepressants were compared and there was no significant difference among the groups who received exercise interventions, medication, or both (Blumenthal et al., 1999). According to what was mentioned earlier, cognitive behavioral therapy and aerobic exercise are effective in treating depression, and cognitive treatment improves depression by affecting automatic negative thoughts and dysfunctional attitudes. This study was an attempt to examine the effects of aerobic exercise on automatic negative thoughts and dysfunctional attitudes. It was also aimed to find what the effects of cognitive therapy are on depression and its cognitive components in comparison to aerobic exercise and the control group.

\section{Methods}

This study was done as clinical trial; the population was all the students of Kermanshah University of medical sciences (KUMS) in 2013. In addition, it is recorded at the Iranian Registry of Clinical Trials (IRCT).

\subsection{Participants}

The sample of this study consisted of 46 associate and undergraduate students from the KUMS, who have been referred to the university counseling centers and recruited after clinical interview to diagnose depression, furthermore, they took the scores of 13 to 28 by completing the Beck Depression Inventory (BDI- II) after the interview. The inclusion criteria were having the score of 13-28 in the BDI-II test, receiving no medications, having strength, consent and willingness to participate in the study. Those who had a significant abnormality other than depression in axis I (using the SCID-I), drug abuse or addiction, abnormality in axis II (using the SCID-II), having suicidal thoughts and having psychotic symptoms such as hallucinations and delusions were excluded from the study. Three groups of cognitive therapy, aerobic exercise and control were equal in terms of demographic characteristics (age, sex, being indigenous and non-indigenous) and the pre-test score of the depression, which was evaluated using a questionnaire.

\subsection{Measures}

The instruments of this study included Beck Depression Inventory- 2nd version (BDI- II), Dysfunctional Attitude Scale (DAS) and Automatic Thoughts Questionnaire (ATQ).

Beck Depression Inventory (BDI-II): This questionnaire is a self report 21-item questionnaire for measuring the severity of depression in adolescents and adults which was reviewed in 1996 to conform to the requirements of DSM-VI for depression. In this questionnaire, the answers are scored 0 to 3 . The BDI-II cut-off point is: $0-13=$ not depressed, 14-19=mild-moderate depression, 20-28=moderate-severe depression and 29-63=severe depression. Higher scores indicate more severe depressive symptoms. BDI-II, based on the Hamilton Rating Scale for Depression has the correlation of $\mathrm{r}=+0.71$, and the reliability of its one week retest is 0.93 (Beck et al., 1996). In a sample of 94 individuals in Iran, psychometric properties were as follows: alpha coefficient of 0.91 , the correlation coefficient between the two halves of 0.89 , and test/retest reliability coefficient of 0.94 (Fata et al., 2005). 
Dysfunctional Attitude Scale (DAS): This scale has been adjusted by Beck and Wissman in 1978. Which, developed based on Beck's cognitive theory of depression and anxiety? DAS consists of two parallel forms, each containing 40 clauses that the participants should comment on it based on the scale containing the complete agreement to complete disagreement. For grading DAS, scores from 1 (completely disagree) to 7 (totally agree) are utilized. However, for number 2, 6, 12, 17, 24, 29, 30,35, 37 and 40, the grading is vice versa in comparison to the other cases. Therefore, the scores will theoretically range from a minimum of 40 to a maximum of 280 . Beck et al. reported the reliability of 0.89 and more for the forms A and B. The correlation between the two tests was reported to be more than 0.81 . In a survey to obtain the reliability coefficient, this test was done and evaluated on 50 participants (18 females, 32 males, with ages ranging from 21 to 36, $(\mathrm{SD}=3.46$ and $\mathrm{M}=25)$ from the Kurdistan Islamic Azad University in the city of Sanandaj. The way of obtaining reliability was a test-retest method with an interval of two weeks. The results showed the reliability coefficient of 0.87 (Rahmani, 1998).

Automatic Thoughts Questionnaire (ATQ): The questionnaire was developed in 1980 by Hollon \& Kendall. In 30 phrases of this questionnaire, some examples of automatic thoughts of depressed patients are presented. Patients will show severity and frequency of their thoughts by selecting options from 1 to 5 . Gharraee in 2003 obtained the reliability coefficient of 0.78 for the beliefs rate and 0.85 for their frequency by implementing the test in a two-week interval 30 female and male students (Naziry, 2004).

\subsection{Procedure}

In the aerobic exercise group, before starting each session, subjects were asked to be on the location (dormitory or campus) 30 minutes earlier to be taught how to measure Radial and Carotid pulse and to have enough practice for them. In order to be sure of the aerobic nature of the exercise, the heart rates were measured. Each exercise session included: measuring and recording resting heart's rate before starting by the Carotid or wrist pulse, starting with warm-up exercises, stretching, breathing, meditation and initial respiration. Typically, the movements started from the head, neck or legs and continued by running in place. This stage took about 10 minutes. Then, the movements were carried on with greater intensity. The average intensity of movements was 0.60 to 0.80 heart rate. This step was faster with gestures and movements of the hands and feet separately, one-way, two-way, and cross legs. At this stage, the heart rate was measured and recorded by Radial or Carotid pulse. Duration of this period was 30 to 35 minutes. The final stage was the cooling down stage with less intensity, lasting for almost 10-15 minutes (Aerobic exercise sessions were conducted under the supervision of an expert sport).

The cognitive therapy group received 12 sessions of cognitive behavior therapy, 2 sessions per week, in the first half of treatment, and 1 session per week for the second half based on the cognitive model of Michael Frey (1996), as presented in the Table 1.

Table 1 . The contents of the cognitive behavior therapy session

\begin{tabular}{ll}
\hline Session & Content \\
\hline 1 & Welcome and presentation of the basic rules of thought and feeling \\
2 & $\begin{array}{l}\text { Cognitive theory, the theory of emotional, approach to identify automatic thoughts and resistance to } \\
\text { treatment }\end{array}$ \\
3 & Behavioral outcomes beliefs, vertical arrow method and advanced vertical arrow \\
4 & Categories beliefs \\
5 & Cognitive maps and the use of ratings(SUD) \\
6 & Test beliefs \\
7 & Homology analysis and useful analysis of beliefs \\
8 & Logical analysis \\
9 & Hierarchy based on cognitive map, Alternative belief and its features \\
10 & Change perceptions and cortical inhibition \\
11 & Discuss your punishment-reward and the use of imagination \\
12 & Review and Closing \\
\hline
\end{tabular}

The members of the control group gathered in a classroom or the amphitheater of the Faculty of Health at KUMS. They tried to discuss the issues raised by themselves. The sessions in all the three groups lasted about 45 to 60 minutes. 


\subsection{Data Analysis}

The statistical analysis was performed using SPSS. For normal distribution of quantitative data, Kolmogorov-Smirnov test, for the homogeneity of variances, the leven's test, for the comparison between groups, one way Analysis of variance (ANOVA) and for the nonparametric equivalent of this test the Kruskal-Wallis test were used. Then, the post hoc tests (Scheffe) were utilized. In terms of the adherence to ethics, the participants in this study were permitted to withdraw from the study in case of aggravating the symptoms, especially suicidal thoughts. The subjects suffered from severe depression were referred to the psychiatrist for treatment. It should be noted that the tasks of the therapy and the evaluation were separately performed by two individuals.

\section{Results}

Among 46 people participated in the study, 16 patients were in the aerobic exercise group ( 3 girls and 13 boys), 16 in the cognitive therapy group ( 4 girls and 12 boys) and 14 in the control group ( 3 girls and 11 boys). The average age in the aerobic exercise group was $20.93 \pm 1.06$, in cognitive therapy group $21.12 \pm 1.25$, and in the control group $20.92 \pm 1.20$ years $(\mathrm{P}=0.938)$. The studied groups were not significantly different in terms of sex, being indigenous or non-indigenous before intervention and the pre-test variable scores $(\mathrm{P}>0.05)$ (Table 2$)$.

Table 2. One way ANOVA for comparing scores of pre-test, posttest and differences between pre-test and post-test in the tree groups

\begin{tabular}{|c|c|c|c|c|c|c|}
\hline \multirow[t]{2}{*}{ variable } & \multirow[t]{2}{*}{ groups } & \multirow{2}{*}{$\begin{array}{l}\text { Pre-test } \\
\text { Mean } \pm \text { SD }\end{array}$} & \multirow[t]{2}{*}{ P-value } & \multirow{2}{*}{$\begin{array}{l}\text { Post-test } \\
\text { Mean } \pm \text { SD }\end{array}$} & \multirow[t]{2}{*}{$\begin{array}{l}\text { Different between } \\
\text { pre-test and post-test }\end{array}$} & \multirow[t]{2}{*}{ p-value } \\
\hline & & & & & & \\
\hline \multirow{3}{*}{ depression } & $\begin{array}{l}\text { Cognitive } \\
\text { therapy }\end{array}$ & $22.62 \pm 3.40$ & & $11.06 \pm 4.13$ & $11.56 \pm 4.5$ & \multirow{3}{*}{0.006} \\
\hline & $\begin{array}{l}\text { Aerobic } \\
\text { exercise }\end{array}$ & $23.12 \pm 3.61$ & 0.76 & $13.31 \pm 5.40$ & $9.81 \pm 7.16$ & \\
\hline & control & $22.70 \pm 4.84$ & & $18.35 \pm 6.14$ & $3.71 \pm 7.68$ & \\
\hline \multirow{3}{*}{$\begin{array}{l}\text { Frequency of negative } \\
\text { automatic thought }\end{array}$} & $\begin{array}{l}\text { Cognitive } \\
\text { therapy }\end{array}$ & $67.50 \pm 19.96$ & & $48.06 \pm 14.59$ & $19.43 \pm 17.82$ & \multirow{3}{*}{0.134} \\
\hline & $\begin{array}{l}\text { Aerobic } \\
\text { exercise }\end{array}$ & $64.31 \pm 20.47$ & 0.72 & $49.43 \pm 14.78$ & $14.87 \pm 18.31$ & \\
\hline & control & $70.28 \pm 20.96$ & & $64.35 \pm 17.14$ & $5.92 \pm 18.43$ & \\
\hline \multirow{3}{*}{$\begin{array}{l}\text { Believe to negative } \\
\text { automatic thought }\end{array}$} & $\begin{array}{l}\text { Cognitive } \\
\text { therapy }\end{array}$ & $66 \pm 17.31$ & & $46.25 \pm 12.60$ & $19.75 \pm 13.02$ & \multirow{3}{*}{0.007} \\
\hline & $\begin{array}{l}\text { Aerobic } \\
\text { exercise }\end{array}$ & $58.81 \pm 15.28$ & 0.27 & $49.18 \pm 15.31$ & $9.62 \pm 13.84$ & \\
\hline & control & $67.42 \pm 14.05$ & & $63.71 \pm 18.28$ & $3.71 \pm 13.33$ & \\
\hline \multirow{3}{*}{ Dysfunctional Attitude } & $\begin{array}{l}\text { Cognitive } \\
\text { therapy }\end{array}$ & $143.62 \pm 24.84$ & & $124.68 \pm 27.19$ & $18.93 \pm 11.44$ & \multirow{3}{*}{0.027} \\
\hline & $\begin{array}{l}\text { Aerobic } \\
\text { exercise }\end{array}$ & $141 \pm 33.10$ & 0.102 & $133.56 \pm 30.43$ & $7.43 \pm 21.49$ & \\
\hline & control & $162.64 \pm 28.74$ & & $161 \pm 29.91$ & $2.53 \pm 13.97$ & \\
\hline
\end{tabular}

To compare the differences among the groups, firstly, their pre-test scores before were subtracted from their post-test scores. Secondly, one way Analysis of variance (ANOVA) and Scheffé's Post hoc test were used to compare and contrast the differences.

Considering the groups, the variables of depression $(\mathrm{P}=0.006)$, believing in automatic negative thoughts $(\mathrm{P}=0.007)$, and dysfunctional attitudes $(\mathrm{P}=0.027)$ were significantly different between the groups after the intervention (Table 2).

In order to find the groups which were significantly different, a Scheffé's test was used. The results of the test revealed that the cognitive group therapy in relation to the control group has caused a significant reduction in depression ( $\mathrm{P}=0.008)$, believing in automatic negative thoughts $(\mathrm{P}=0.008)$, and dysfunctional attitudes $(\mathrm{P}=0.036)$. However, comparing both groups regarding the frequency of believing in automatic negative thoughts, there was 
no significant difference. Although aerobics in the control group causes more reductions in the variables, It was only meaningful for the depression variable $(\mathrm{P}=0.049)$. Additionally, the cognitive therapy group shows more reductions comparing with aerobics exercises group; however, they are not statistically significant (Table 3 ).

Table 3. Scheffe test for comparing scores of differences between pre-test and post-test in the tree group

\begin{tabular}{|c|c|c|c|c|}
\hline variable & (i) Groups & (j)Groups & Mean Difference (I-j) & p-value \\
\hline \multirow{3}{*}{ Depression } & \multirow{2}{*}{ Cognitive therapy } & Aerobic exercise & 1.75 & 0.75 \\
\hline & & control & 7.84 & 0.008 \\
\hline & Aerobic exercise & control & 6.09 & 0.049 \\
\hline \multirow{3}{*}{ Frequency of negative automatic thought } & \multirow{2}{*}{ Cognitive therapy } & Aerobic exercise & 4.56 & 0.77 \\
\hline & & control & 13.50 & 0.14 \\
\hline & Aerobic exercise & control & 8.94 & 0.41 \\
\hline \multirow{2}{*}{ Believe to negative automatic thought } & \multirow{2}{*}{ Cognitive therapy } & Aerobic exercise & 10.12 & 0.114 \\
\hline & & control & 16.03 & 0.008 \\
\hline \multirow{3}{*}{ Dysfunctional attitude } & \multirow{2}{*}{ Cognitive therapy } & Aerobic exercise & 11.5 & 0.151 \\
\hline & & control & 16.39 & 0.036 \\
\hline & Aerobic exercise & control & 4.89 & 0.72 \\
\hline
\end{tabular}

\section{Discussion}

The present study has demonstrated that the cognitive group therapy significantly caused more meaningful reductions in depression, automatic negative thoughts and dysfunctional attitudes than the control group. The meaningful reduction in depression after 12 sessions of cognitive-behavioral therapy is in line with the findings of Wong (2008) Taheri and Jamshidifar (2007), Ranjbar et al. (2010) Forouzande et al (2003)

Along with the findings of Oei et al., the results of this study demonstrated that the cognitive-behavioral therapy causes meaningful reductions in automatic negative thoughts, believing in automatic thoughts and dysfunctional attitudes (Oei et al., 2006).

According to Beck depression model, experience in individuals would result in making assumptions and schema about the self and the environment. These assumptions play crucial roles in organizing cognition and behavior control. If these assumptions are inflexible and extreme, they are dysfunctional and if they are activated, they will cause automatic negative thoughts which are related to undesirable excitements leading to depression's symptoms. The more the automatic negative thoughts, the more depressed the individual. Cognitive therapist can help to break this vicious circle (Hawton et al., 1989).

Moreover, the results are in accordance with the casual cognitive model. This model suggests that automatic negative thoughts and dysfunctional attitudes are involved in the beginning and the maintenance of depression. Cognitive intervention firstly targets the automatic negative thoughts, which are the mediator of depression; then it will focus on replacing them with more compatible thoughts. According to theory, reduction in negative automatic thoughts should bring about a reduction in depressive symptoms. Next, the dysfunctional attitudes that are replaced by more realistic ones should further reduce negative automatic and depressive symptoms (Oei et al., 2006).

The findings of the present study also demonstrates that the participant in aerobic exercise group have shown significant reduction in the scores of depression in comparison to the control group. This is compatible with the findings of Nabkasorn et al. (2006), McCann and Holmes (1984), Dimeo et al. (2001) Zarshenas et al. (2008) and Craft (2005).

As several factors might be at work, one is biological processes. The reported data is in congruous with the assumption that in behavioral disorders, maladjustments in biological amines could be responsible. Norepinephrine and Serotonin neurotransmitter are among the biological amines which have the highest level of intervention in Pathophysiology of mood disorders. However, there are theories considering the role of Dopamine in depression as well. It seems that in depression disorders, the level of this neurotransmitter decreases (Sadock et al., 2007). A number of studies have examined the levels of Noradrenalin, Serotonin and Dopamine while exercising. Although there were significant differences in experimental protocols, the results have shown that there are changes in Synthesis and monoamine metabolism during exercising (Meeusen \& De 
Meirleir, 1995). There have even been studies demonstrating that exercising could change the concentration of Neurotransmitter (Chaouloff, 1997). Thusly, physical exercise might be a therapeutic strategy in treating severe depression because of evacuation of neurotransmitters (Sadock et al., 2007). According to British National Association of Health, exercising increases the level of Serotonin in the brain (Hemat-Far et al., 2012).

Another factor for justifying the results of this study might be related to psychological variables. For instance, in a study Craft et al. demonstrated that not only exercising decreases depression but also increases self-esteem (Craft et al., 2005). Foley et al. also showed that the severity of depression has a significant negative relationship with changes in coping efficacy and episodic memory. Generally speaking, this study demonstrated that physical exercises are related to positive cognitive and psychological changes in patients with depression (Foley et al., 2008).

Another model for explaining this study is that of distraction or Time-out Hypothesis. It suggests that through the act of engaging in exercise, a psychological release is provided from the primary source of worry or depression (Alfermann \& Stoll, 2000). Considering that in the control group the element of distraction was present, this might be one of the reasons of the significant differences between the groups. Although the cognitive therapy group shows more reductions comparing to aerobics exercises group, they are not statistically significant. This might be a result of distraction in cognitive group therapy in the control group. Somehow, participants' attention was drawn to the issues being discussed in the sessions; ergo they were distracted from the sources of anxiety. Hence, there negative thoughts were decreased. Perhaps, this matter is one of the reasons that the variable of cognition was not significant in comparison to the aerobic exercise and the control group.

Additionally, the result of this study indicates that there is no significant difference between cognitive-behavioral and aerobics therapy. This is in congruous with the findings of Lawlor and Hopker (2001), Fremont and Craighead (1987). As far as the researchers know, there is no research on comparing the impact of aerobics and cognitive therapies on the variables of automatic negative thoughts, its frequency and dysfunctional attitudes.

\section{Conclusion}

According to the results of the present study, both cognitive-behavioral and aerobics therapy are effective in the treatment of depression. Accordingly, aerobics could be employed alone in the treatment schedule of patients suffering from depression or with cognitive therapy and pharmacotherapy. Aerobics is easy to learn and requires no specialist not to mention the fact that it is cheaper than cognitive-behavioral therapy. Thus, aerobics is better than cognitive therapy in terms of expenses and availability. However, cognitive-behavioral therapy reduces depression and its cognitive symptoms more. Moreover, in the long run, it probably has better results than aerobics therapy. Considering the limits of the present study, this was not possible to investigate in this study.

\section{Acknowledgments}

This work was performed in partial fulfillment of the requirements for M.Sc degree of Mr. Seyed mojtaba ahmadi, Kermanshah University of Medical Sciences, Kermanshah, Iran, and was financially supported by a grant from Kermanshah University of Medical Sciences office of Vice Chancellor for Research, Kermanshah, Iran.

Hereby the authors express their special thanks to the education and research vice president of Kermanshah University of Medical Science, officials of Faculty of Health, students and colleagues for their help.

\section{Conflict of Interest}

The authors declare that there is no conflict of interests regarding the publication of this paper.

\section{References}

Alfermann, D., \& Stoll, O. (2000). Effects of Physical Exercise on Self-Concept and Well Being. In D. Lavallee, J. Kremer, A. P. Moran, \& M. Williams (Eds.), Sport psychology: Contemporary Themes. New York: Palgrave Macmillan.

Beck, A. T., Steer, R. A., \& Brown, G. K. (1996). Manual for the Beck Depression Inventory-II. In H. Yaghobi (Ed.), Screening for mental disorders: Position of tests and how to determine the cut score and Validation. Journal of Mental Health, 1(1), 39-51.

Blumenthal, J. A., Babyak, M. A., Moore, K. A., Craighead, W. E., Herman, S., Khatri, P., ... Appelbaum, M. (1999). Effects of exercise training on older patients with major depression. Archives of internal medicine, 159(19), 2349. http://dx.doi.org/10.1001/archinte.159.19.2349

Chaouloff, F. (1997). Effects of acute physical exercise on central serotonergic systems. Medicine \& Science in 
Sports \& Exercise, 29(1), 58-62. http://dx.doi.org/10.1097/00005768-199701000-00009

Craft, L. L. (2005). Exercise and clinical depression: Examining two psychological mechanisms. Psychology of Sport and Exercise, 6(2), 151-171. http://dx.doi.org/10.1016/j.psychsport.2003.11.003

Dimeo, F., Bauer, M., Varahram, I., Proest, G., \& Halter, U. (2001). Benefits from aerobic exercise in patients with major depression: A pilot study. British Journal of Sports Medicine, 35(2), 114-117. http://dx.doi.org/ 10.1136/bjsm.35.2.114

Fata, L., Birashk, B., Atefvahid, M. K., \& Dabson, K. S. (2005). Meaning Assignment Structures/Schema, Emotional States and Cognitive Processing of Emotional Information: Comparing Two Conceptual Frameworks. Iranian journal of psychiatry and clinical psychology, 11(3), 312-326.

Foley, L. S., Prapavessis, H., Osuch, E. A., De Pace, J. A., Murphy, B. A., \& Podolinsky, N. J. (2008). An examination of potential mechanisms for exercise as a treatment for depression: A pilot study. Mental Health and Physical Activity, 1(2), 69-73. http://dx.doi.org/10.1016/j.mhpa.2008.07.001

Forouzande, N., Delaram, M., Solati, S., Aein, F., \& Deris, F. (2003). Effect of cognitive behavioral therapy on depression of non-medical students of Shahrekord University of Medical Sciences. Joural of Shahrekord University of Mededical Sciences, 4(4), 7-11.

Free, M. (1999). Cognitive therapy in groups: Guidelines and resources for practice. Translated by M. Mohammadi, \& R. Farnam (2005). Tehran: Roshd.

Fremont, J., \& Craighead, L. W. (1987). Aerobic exercise and cognitive therapy in the treatment of dysphoric moods. Cognitive Therapy and Research, 11(2), 241-251. http://dx.doi.org/10.1007/BF01183268

Hashemi, N., \& Kamkar, A. (2001). A study on the prevalence of depression in student of Yasuj University of Medical Sciences. Journal of Yasuj Medical Sciences University, 6(21-22), 14-22.

Hawton, K. E., Salkovskis, P. M., Kirk, J. E., \& Clark, D. M. (1989). Cognitive behaviour therapy for psychiatric problems: A practical guide. Oxford University Press. http://dx.doi.org/10.1093/med:psych /9780192615879.001.0001

Hemat-Far, A., Shahsavari, A., \& Mousavi, S. R. (2012). Effects of Selected Aerobic Exercises on the Depression and Concentrations of Plasma Serotonin in the Depressed Female Students Aged 18 to 25 . Journal of Applied Research in Clinical and Experimental Therapeutics, 12(1), 47.

Ildarabady, E., Firouz Kouhi, M., Mazloum, R., \& Navidian, A. (2004). Prevalence of depression among students of Zabol medical school. Journal of Shahrekord University of Medical Sciences, 6(2), 15-21.

Kahrizi, E., Agha Yousefi, A. R., \& Mirhashemi, M. (2012). The effect of cognitive group therapy on reducing depression in prisoners based on michael ferry's method. Andisheh Va Raftar (Applied Psychology), 6(22), 21-30.

Lawlor, D. A., \& Hopker, S. W. (2001). The effectiveness of exercise as an intervention in the management of depression: Systematic review and meta-regression analysis of randomised controlled trials. BMJ: British Medical Journal, 322(7289), 763. http://dx.doi.org/10.1136/bmj.322.7289.763

McCann, I. L., \& Holmes, D. S. (1984). Influence of aerobic exercise on depression. Journal of personality and social psychology, 46(5), 1142. http://dx.doi.org/10.1037/0022-3514.46.5.1142

Meeusen, R., \& De Meirleir, K. (1995). Exercise and brain neurotransmission. Sports Medicine, 20(3), 160-188. http://dx.doi.org/10.2165/00007256-199520030-00004

Nabkasorn, C., Miyai, N., Sootmongkol, A., Junprasert, S., Yamamoto, H., Arita, M., \& Miyashita, K. (2006). Effects of physical exercise on depression, neuroendocrine stress hormones and physiological fitness in adolescent females with depressive symptoms. The European Journal of Public Health, 16(2), 179-184. http://dx.doi.org/10.1093/eurpub/cki159

Naziry, G. H. (2004). A Study of application and effectiveness of metaphors in the process of cognitive behavior therapy of depressed patients PhD thesis in clinical psychology: Tehran psychiatry institude, Iran University of medical sciences.

Oei, T. P., Bullbeck, K., \& Campbell, J. M. (2006). Cognitive change process during group cognitive behaviour therapy for depression. Journal of affective disorders, 92(2), 231-241. http://dx.doi.org/10.1016/j.jad.2006. 02.004

Rahmani, F. (1998). Comparison of dysfunctional attitudes among the treated depressed patients, untreated 
depressed patients and normal subjects Master's thesis in clinical psychology. Tehran Psychiatry instatude, Iran University of Medical Sciences.

Ranjbar, F., Ashktorab, T., \& Dadgary, A. (2010). Effectiveness of group cognitive-behavioral therapy on depression. Journal of Shaheed Sadoughi University of Medical Sciences, 18(4), 299-306.

Sadock, B. J., Kaplan, H. I., \& Sadock, V. A. (2007). Kaplan \& Sadock's Synopsis of Psychiatry/behavioral Sciences/Clinical Psychiatry (10th ed.). Philadelphia: Lippincott Williams \& Willkins.

Taheri, A., \& Jamshidifar, Z. (2007). The Effectiveness of Cognitive Group Therapy on Decreasing the Symptoms of Depression. Applied Psychology, 1(3), 51-56.

Tavakoli Zade, J., \& Mohamadpoor, A. (2001). Study of prevalence of depression in students of Gonabad university of medical sciences. Journal of Gonabad University of Medical Sciences, 7(1), 26-40.

Wong, D. F. K. (2008). Cognitive behavioral treatment groups for people with chronic depression in Hong Kong: A randomized wait-list control design. Depression and Anxiety, 25(2), 142-148. http://dx.doi.org/10.1002/ da. 20286

Zarshenas, S., Karbalaey, A., Hosseini, A., Moshtagh, N., \& Rahgozar, M. (2008). The Effect of aerobic exercises on depression among Adult Women. Journal of Research in Rehabilitation Sciences, 4(1), 9-15.

Zohoor, A., \& Mosakhani, E. (2001). The prevalence of depression among Kerman's health faculty and it's comparison with other Iranian universities. Quarterly of Lorestan University of Medical Sciences, 10, 43-47.

\section{Copyrights}

Copyright for this article is retained by the author(s), with first publication rights granted to the journal.

This is an open-access article distributed under the terms and conditions of the Creative Commons Attribution license (http://creativecommons.org/licenses/by/3.0/). 